BMJ Open

Diabetes

Research

\& Care

\title{
Impact of malnutrition on survival and healthcare utilization in Medicare beneficiaries with diabetes: a retrospective cohort analysis
}

\author{
Naseer Ahmed, ${ }^{1}$ Yong Choe, ${ }^{1}$ Vikkie A Mustad, ${ }^{1}$ Sumita Chakraborty, ${ }^{1}$ \\ Scott Goates, ${ }^{1}$ Menghua Luo, ${ }^{1}$ Jeffrey I Mechanick ${ }^{2}$
}

\begin{abstract}
To cite: Ahmed N, Choe Y, Mustad VA, et al. Impact of malnutrition on survival and healthcare utilization in Medicare beneficiaries with diabetes: a retrospective cohort analysis. BMJ Open Diab Res Care 2018;6:e000471. doi:10.1136/ bmjdrc-2017-000471
\end{abstract}

77th Annual ADA Scientific Sessions, poster, health care delivery-economics, 173-LB, 2017.

Received 7 September 2017 Revised 9 November 2017 Accepted 21 November 2017

Check for updates

${ }^{1}$ Research and Development, Abbott Nutrition, Columbus, Ohio, USA

${ }^{2}$ Divisions of Cardiology and Endocrinology, Diabetes and Bone Disease, Icahn School of Medicine at Mount Sinai, Mount Sinai School of Medicine, New York, USA

\section{Correspondence to} Dr Vikkie A Mustad; vikkie.mustad@abbott.com

\section{ABSTRACT}

Objective The aim of this study was to examine the impact of pre-existing malnutrition on survival and economic implications in elderly patients with diabetes. Research design and methods A retrospective observational study was conducted to examine the impact of malnutrition with or without other significant health conditions on survival time and healthcare costs using the Centers for Medicare and Medicaid Services (CMS) data from 1999 to 2014 for beneficiaries with a confirmed first date of initial diagnosis of diabetes ( $\mathrm{n}=15121131)$.

The primary outcome was survival time, which was analyzed using all available data and after propensity score matching. Healthcare utilization cost was a secondary outcome.

Results A total of 801272 beneficiaries were diagnosed with malnutrition. The analysis on propensity scorematched data for the effect of common conditions on survival showed that the risk for death in beneficiaries with diabetes increased by $69 \%$ in malnourished versus normonourished (HR, 1.69; $99.9 \% \mathrm{Cl} 1.64$ to $1.75 ; \mathrm{P}<0.0001$ ) beneficiaries. Malnutrition increased the risk for death within each of the common comorbid conditions including ischemic heart disease (1.63; 1.58 to 1.68), chronic obstructive pulmonary disorder $(1.60 ; 1.55$ to 1.65$)$, stroke or transient ischemic attack (1.57; 1.53 to 1.62$)$, heart failure $(1.54 ; 1.50$ to 1.59$)$, chronic kidney disease (1.50; 1.46 to 1.55$)$, and acute myocardial infarction $(1.47 ; 1.43$ to 1.52 ). In addition, the annual total spending for the malnourished beneficiaries was significantly greater than that for the normo-nourished beneficiaries ( $\$ 36079$ vs 20 $787 ; \mathrm{P}<0.0001)$.

Conclusions Malnutrition is a significant comorbidity affecting survival and healthcare costs in CMS beneficiaries with diabetes. Evidence-based clinical decision pathways need to be developed and implemented for appropriate screening, assessment, diagnosis and treatment of malnourished patients, and to prevent malnutrition in normo-nourished patients with diabetes.

\section{INTRODUCTION}

Diabetes is a debilitating disease of epidemic proportions, both domestically and globally. According to the $\mathrm{WHO},{ }^{1}$ the prevalence of diabetes in adults increased from $4.7 \%$ in 1980

\section{Significance of this study}

What is already known about this subject?

- Malnutrition increases morbidity, but in diabetes is not studied due to the prevailing obesity or overweight conditions.

What are the new findings?

- This retrospective study using the Centers for Medicare and Medicaid Services data shows malnutrition in beneficiaries with diabetes worsens survival and increases healthcare costs.

How might these results change the focus of research or clinical practice?

- This study underlies the importance of concentrated efforts in identification and treatment of malnutrition in patients with diabetes.

to $8.5 \%$ in 2014 worldwide. In the USA alone, the prevalence of diabetes (diagnosed and undiagnosed) was $25.9 \%$ in $2012 .^{2}$ Diabetes exerts a substantial clinical and economic burden in the USA, with an estimated cost of $\$ 245$ billion in 2012 due to an increased use of healthcare and reduced productivity. ${ }^{3}$ The prevalence of diabetes among adults aged 65 years or older is more than $25 \%$, with this rate being projected to double by 2050 , in part due to the aging of the overall population in the USA. ${ }^{4}$ Patients in this age group have considerable risks for amputation, myocardial infarction, end-stage renal disease, and other diabetes-related complications. ${ }^{5}$

Malnutrition is also a common, but frequently under-recognized, health concern in older adults. ${ }^{6}$ Depending on the screening and assessment methods used, malnutrition is present in $5 \%-30 \%$ of community-dwelling older adults. ${ }^{6}$ Although the term 'malnutrition' is most often associated with undernutrition, it can also result from overnutrition, specific nutrient 
deficiencies, increased dietary requirements, or poor nutrient absorption, or increased nutrient losses due to certain diseases. ${ }^{7}$ Malnutrition is often used as a general term that encompasses cachexia, sarcopenia, and inadequate nutrient intake. ${ }^{7}$ Acute or chronic diseases and treatment interventions may also lead to the aggravation of malnutrition, especially undernutrition, due to changes in metabolism. ${ }^{8}$ This disease-related malnutrition complicates treatment plans and negatively impacts patient outcomes such as recovery time, risk for complications, and readmission rates, which exert a greater pressure on health services. ${ }^{9}{ }^{10}$ Hence, there is a growing recognition of the importance of malnutrition on health-related and economic outcomes. ${ }^{11} 12$

Several factors, including diagnosis of diabetes and older age ( $>65$ years), have been shown to be associated with an increased risk for malnutrition. ${ }^{13}$ Unfortunately, malnutrition in older adults is poorly understood and most likely underdiagnosed, especially in those who are overweight or obese. By using the data from 2011 to 2014, the National Center for Health Statistics reported that $37 \%$ of the adults were aged 60 years and older and also obese. ${ }^{14}$ The risk for malnutrition increases with age and number of comorbidities $^{6}$; however, the precise estimates among those with diabetes are unknown. One multicenter observational study of hospitalized, elderly patients with diabetes reported that $39 \%$ of the patients had risks for malnutrition and an additional 21\% had malnutrition, and both were unrelated to body mass index (BMI). ${ }^{15}$ Malnutrition in geriatric patients, especially those with diabetes, leads to impaired muscle function and wound healing, decreased bone mass, immune dysfunction, and general functional decline. ${ }^{13}$

The current evidence indicates that there is a large population of patients with both malnutrition and diabetes who would be expected to have worse outcomes and higher healthcare costs than those with diabetes alone; however, these relationships need to be clarified. Therefore, the purpose of this large retrospective study is to examine the impact of pre-existing malnutrition on survival and economic implications in elderly patients with diabetes by using propensity score-matched cohorts of Medicare beneficiaries.

\section{RESEARCH DESIGN AND METHODS}

\section{Data source}

A retrospective observational study was designed to examine the impact of malnutrition and chronic conditions on survival by using the Centers for Medicare and Medicaid Services (CMS) claims database. Medicare is the national health insurance program in the USA for people aged 65 years or older, certain younger people with disabilities, and people with end-stage renal disease. ${ }^{16}$ The CMS hosts a warehouse of 27 chronic conditions for researchers to facilitate investigations to improve quality of care and reduce costs and utilization. The Chronic Conditions Data Warehouse definition of the first date of diagnosis was used, for seven selected chronic conditions, namely acute myocardial infarction (AMI), chronic kidney disease (CKD), chronic obstructive pulmonary disease (COPD), heart failure (HF), ischemic heart disease (IHD), lung cancer, and stroke or transient ischemic attack (TIA). ${ }^{17}$ These seven chronic conditions along with malnutrition have been referred to as common conditions. The authors submitted a protocol and signed a data use agreement with the CMS. On approval, the authors were granted access to Research Identifiable Files from the CMS through a secure CMS Virtual Research Data Center to conduct this analysis.

\section{Study population}

Data from January 1, 1999 to December 31, 2014 were procured for beneficiaries who had a diagnosis of diabetes $(\mathrm{n}=25799$ 975). Patients were included in this analysis cohort (AC) if they had been in the database for at least 1 year without the diagnosis of diabetes. The first date of diagnosis of diabetes was defined as time zero (TZ).

This inclusion criterion resulted in an AC of 15121131 beneficiaries (15 121 131/25 799 975=58.61\%). The AC was broadly segregated into two groups: malnourished group (MNG) and normo-nourished group (NNG). The MNG ( $n=801272)$ consisted of beneficiaries with a diagnosis of at least one of the following International Classification of Diseases, Ninth Revision (ICD-9) codes before TZ: 260 (Kwashiorkor), 261 (nutritional marasmus), 262 (other severe, protein-calorie malnutrition), 263 (other unspecified protein-energy malnutrition), 263.0 (moderate malnutrition), 263.1 (mild malnutrition), 263.2 (arrested development following protein-calorie malnutrition), 263.8 (other protein-calorie malnutrition), 263.9 (unspecified protein-calorie malnutrition), or 783.22 (underweight) (figure 1, table 1). The transition to ICD-10 was in 2015 and thus was not used in this analysis. The NNG ( $\mathrm{n}=14319859)$ consisted of beneficiaries without any of the above-mentioned ICD-9 codes before TZ.

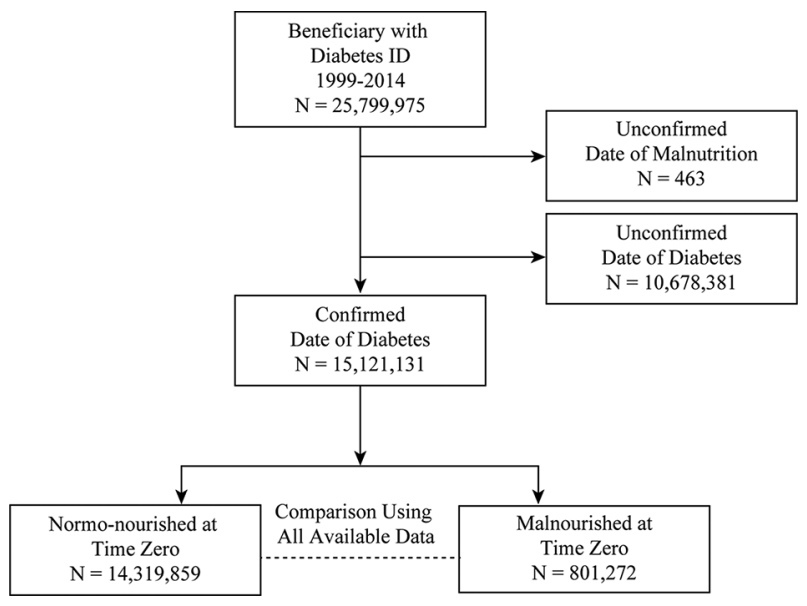

Figure 1 Study cohorts. 


\begin{tabular}{|c|c|c|}
\hline ICD-9 & $\begin{array}{l}\text { Codes and description for } \\
\text { malnutrition }(\mathrm{N}=801272)\end{array}$ & Percent* \\
\hline 263.9 & $\begin{array}{l}\text { Unspecified protein-calorie } \\
\text { malnutrition }\end{array}$ & 74.76 \\
\hline 263.0 & Moderate malnutrition & 14.56 \\
\hline 262 & $\begin{array}{l}\text { Other severe, protein-calorie } \\
\text { malnutrition }\end{array}$ & 9.68 \\
\hline 263.1 & Mild malnutrition & 8.24 \\
\hline 261 & Nutritional marasmus & 8.04 \\
\hline 263.8 & Other protein-calorie malnutrition & 5.58 \\
\hline 260 & Kwashiorkor & 4.27 \\
\hline 783.22 & Underweight & 2.95 \\
\hline 263.2 & $\begin{array}{l}\text { Arrested development following } \\
\text { protein-calorie malnutrition }\end{array}$ & 0.50 \\
\hline 263 & $\begin{array}{l}\text { Other unspecified protein-energy } \\
\text { malnutrition }\end{array}$ & 0.07 \\
\hline
\end{tabular}

*Beneficiaries could have one or more ICD- 9 codes. The transition to ICD-10 codes was in 2015 and thus was not used in this analysis.

ICD-9, International Classification of Diseases, Ninth Revision.

\section{Outcomes}

The primary outcome variable for this retrospective study was survival time: calculated as time from TZ to death (if death was observed) or censored at December 31, 2014 (if the survival was documented beyond this date). The secondary variables were annual healthcare utilizations, including annual total costs (Medicare parts A, B, D, and combined); annual number of acute and other inpatient, skilled nursing facility (SNF) and hospice covered days; annual number of acute and other inpatient, SNF and hospice stays; and annual number of hospital readmissions. $^{18}$

\section{Statistical analysis}

Three primary analyses were performed. The first analysis evaluated the effect of common conditions on survival. All available data (AAD) for common conditions were generated as two cohorts as follows: a case cohort with the first diagnosis date of the condition before TZ and a control cohort without the diagnosis of the condition before TZ. The survival analysis of AAD and propensity score-matched samples was performed by using a Cox proportional hazard model with a robust variance estimator, ${ }^{19}$ adjusting for age, gender, ethnoracial identity, and 26 other disease conditions (indicators for having or not having the disease condition) with two exceptions: the analysis for AMI did not include IHD as a covariate and the analysis for IHD did not include AMI as a covariate (all patients having AMI at baseline also had IHD). The case and control cohorts underwent propensity score matching for each of the common conditions using a greedy matching method. ${ }^{20}$ The propensity scores were generated using the set of covariates included in the survival analysis. Propensity score matching was performed by randomly selecting 40064 ( $5 \%$ of MNG) of the case group followed by propensity score matching without replacement with a five-time larger randomly selected patient population $(5 \times 40064=200320)$ from the control group. Each beneficiary in the case group was matched with a beneficiary in the control group with the closest logit propensity score within a caliper width (maximum difference) of $0.2 \mathrm{SD}$ of the logit propensity score. ${ }^{20}$ In case of equal matching of more than one beneficiary, one of them was selected randomly. ${ }^{21}$ This propensity score matching approach was used for all common conditions. This approach was adopted to ensure that the resulting propensity score-matched data sets were comparable with the propensity score-generating variables, ${ }^{22}$ thus reducing or eliminating the effects of confounding factors. ${ }^{20}$ Survival of the beneficiaries in the case versus control cohorts was compared by using two-sided 0.001 level tests. The $\mathrm{P}$ values, HRs, and 99.9\% CIs were reported for each of the constituent conditions.

The second analysis was performed to evaluate the effect of malnutrition within each common condition by using a similar approach to the first analysis, which did not include IHD as a covariate within AMI, and the analysis within IHD did not include AMI as a covariate. A similar approach to the first analysis was used for propensity score matching within all other common conditions, except for lung cancer. Within lung cancer, all malnourished beneficiaries at baseline $(n=28961)$ were matched with all normo-nourished beneficiaries (207 965), because the number of all malnourished beneficiaries with lung cancer at $\mathrm{TZ}$ was small $(\mathrm{n}<40064)$.

The third analysis was performed on the annual healthcare utilizations to compare the MNG and NNG cohorts by using the propensity score-matched sample. Data were obtained from the Medicare Master Beneficiary Cost Summary - Cost and Use file from 1999 to 2014. The healthcare cost for each beneficiary in the propensity score-matched data set was derived from Medicare parts $\mathrm{A}, \mathrm{B}$, and $\mathrm{D} .^{23}$ The annual medical spending for each beneficiary was calculated from the year of $\mathrm{TZ}$ to the year of death or 2014. The propensity score-matched differences (MNG - NNG) were tested by using a two-sided Wilcoxon signed-rank (0.001 level) test. The $\mathrm{P}$ values, median values for MNG and NNG, and the difference (MNG - NNG) with 99.9\% CI were reported by using only the matched pairs included in the test. The annual variables (per year), acute inpatient covered days, other inpatient covered days, SNF covered days, and hospice covered days, acute inpatient stays, other inpatient stays, SNF stays, hospice stays, and hospital readmissions were categorized into two categories. The two categories were created in response to the following question: Is the value of the variable for this cohort greater than the value of the other cohort? The categorized variables were analyzed by generalized estimating equations adjusted for age, gender, ethnoracial identity, and 26 other disease conditions. The OR, 99.9\% CIs, and $\mathrm{P}$ values were reported. 
Statistical software SAS V.9.4 and SAS Enterprise Guide V.7.1 were used for all analyses.

\section{RESULTS}

The baseline demographic information of the MNG and NNG cohorts for AAD and propensity score-matched sample is presented in table 2. The MNG and NNG cohorts differed in terms of age, gender, and ethnoracial identity. The mean $( \pm \mathrm{SD})$ age of the MNG beneficiaries was $75.4( \pm 13.3)$ years, and $57.63 \%$ were women, $74.93 \%$ were whites, and $18.10 \%$ were blacks. The mean $( \pm \mathrm{SD})$ age of the NNG beneficiaries was $71.3( \pm 11.4)$ years, and $52.79 \%$ were women, $79.24 \%$ were whites, and $12.58 \%$ were blacks. The cohorts also differed in terms of chronic conditions. However, after propensity score matching, the MNG and NNG cohorts were comparable for all variables (table 2).

The analysis of AAD for the effect of common conditions on survival showed that the risk for death in beneficiaries with malnutrition was higher (HR, 1.66; 99.9\% CI 1.65 to $1.66 ; \mathrm{P}<0.0001$ ) than for other conditions such as IHD, AMI, stroke or TIA, COPD, CKD, and HF, except for lung cancer, for which the risk was the highest (HR, $2.70 ; 2.68$ to 2.72 ), as shown in table 3 .

The analysis of AAD for the effect of malnutrition within each of other seven common conditions showed that malnutrition had significant effect on survival (all $\mathrm{P}<0.0001)$. The greatest impact of malnutrition on survival was within COPD (HR, 1.66; 99.9\% CI 1.64 to 1.67) and the smallest impact of malnutrition on survival was within AMI (HR, 1.47; 1.44 to 1.49) (table 3).

The analysis of propensity score-matched data for the effect of common conditions on survival exhibited the same trend as $\mathrm{AAD}$ with the risk for death in beneficiaries with malnutrition increasing by $69 \%$ (HR, $1.69 ; 99.9 \% \mathrm{CI}$ 1.64 to $1.75 ; \mathrm{P}<0.0001)$. Other conditions that conferred an increased risk for death were IHD (HR, 1.06; 1.02 to 1.10 ), AMI (HR, $1.19 ; 1.15$ to 1.23 ), stroke or TIA (HR, $1.21 ; 1.18$ to 1.26 ), COPD (HR, $1.43 ; 1.38$ to 1.48 ), HF (HR, $1.50 ; 1.45$ to 1.56 ), CKD (HR, $1.58 ; 1.53$ to 1.64 ) and lung cancer (HR, 2.48; 2.41 to 2.56 ). The $\mathrm{P}$ value was $<0.0001$ for all as shown in figure $2 \mathrm{~A}$. The KaplanMeier survival curve for time to death from diagnosis of diabetes after propensity score matching revealed that the median survival times for the MNG and NNG were 2.38 and 5.08 years, respectively (figure 3 ).

The analysis of the effect of malnutrition on survival within the common conditions demonstrated that malnutrition had a significant effect in every case (all $\mathrm{P}<0.0001)$. The increased risk for death ranged from $47 \%$ within AMI (HR, $1.47 ; 99.9 \%$ CI 1.43 to 1.52 ) to $63 \%$ within IHD (HR, 1.63 ; 1.58 to 1.68 ) (figure 2B). Malnutrition significantly increased the risk for death by $50 \%$ within CKD (HR, $1.50 ; 1.46$ to 1.55 ), $54 \%$ within HF (HR, $1.54 ; 1.50$ to 1.59 ), $57 \%$ within stroke or TIA (HR, 1.57 ; 1.53 to 1.62$)$ and $60 \%$ in COPD (HR, $1.60 ; 1.55$ to 1.65 ) (figure 2B).
The healthcare utilization data for the MNG and NNG are presented in tables 4 and 5 . The average annual healthcare cost for the individuals in the MNG (table 4) was 1.7 times greater than those in the NNG (median, $\$ 36079$ vs $\$ 20787 ; \mathrm{P}<0.0001)$. The bulk of this difference (median, $\$ 8775 ; \mathrm{P}<0.0001$ ) was from Medicare part $\mathrm{A}$, with a smaller contribution from Medicare part $\mathrm{B}$ (median, \$2113; $\mathrm{P}<0.0001$ ). The annual spending in Medicare part $\mathrm{D}$ was not different between the MNG and NNG ( $\mathrm{P}=0.87$; table 4 ). All ORs (odds of greater number in $\mathrm{MNG}$ over odds of greater number in $\mathrm{NNG}$ ) were statistically significant $(\mathrm{P}<0.0001)$ and greater than one acute inpatient covered days per year, other inpatient covered days per year, SNF covered days per year, hospice covered days per year, acute inpatient stays per year, other inpatient stays per year, SNF stays per year, hospice stays per year and hospital readmissions per year (table 4). Acute inpatient covered days per year had the highest OR of 3.08 (99.9\% CI 2.87 to 3.30), meaning for a matched pair in the sample, the odds were $3.08: 1$ that the subject in the MNG group had more acute inpatient covered days than the subject in the NNG group. The other ORs in table 5 have similar interpretations. The MNG beneficiaries had 2.50-fold (2.33 to 2.67) and 2.08-fold (1.94 to 2.24) odds of higher acute and other inpatient stays, respectively, compared with the NNG beneficiaries (table 5).

\section{DISCUSSION}

Worldwide, the prevalence of diabetes continues to rise among adults, with over a quarter of US adults aged 65 years or older being affected. A WHO multinational study of vascular disease in diabetes confirmed that cardiovascular disease and renal disease accounted for $52 \%$ and $11 \%$ of the deaths, respectively, in patients with diabetes. ${ }^{24}$ Recently, a study by the Emerging Risk Factors Collaboration group demonstrated that in addition to vascular disease, diabetes is associated with increased mortality due to cancer, infectious diseases, liver disease, intentional selfharm, COPD, and other causes. ${ }^{25}$ However, malnutrition is not commonly listed as a comorbidity of diabetes, although there is evidence to indicate worsening of clinical outcomes when diabetes is associated with poor nutritional status, especially in geriatric patients. ${ }^{15}{ }^{26}$ Malnutrition is estimated at $29 \%-61 \%$ in an elderly hospital population and is shown to be associated with markedly increased morbidity and mortality, lower quality of life (QoL), and increased healthcare costs. ${ }^{27-29}$ This is the first large retrospective cohort study to directly analyze the impact of malnutrition and common comorbid conditions on survival and annual healthcare utilization in elderly patients with diabetes by using the CMS claims database. The effect of common comorbid conditions including malnutrition on survival was analyzed for $\mathrm{AAD}$ as well as by propensity score matching by comparing the cohort having the condition with the cohort not having the condition at TZ, the first date of diagnosis of diabetes. The overall frequency of protein-energy malnutrition (PEM) in the Medicare population of over 15 million 
Table 2 Baseline characteristics of the study participants

\begin{tabular}{|c|c|c|c|c|}
\hline \multirow[b]{2}{*}{ Characteristics } & \multicolumn{2}{|c|}{ All available data } & \multicolumn{2}{|c|}{ Propensity-matched sample } \\
\hline & $\begin{array}{l}\text { MNG } \\
n=801272\end{array}$ & $\begin{array}{l}\text { NNG } \\
n=14319859\end{array}$ & $\begin{array}{l}\text { MNG } \\
n=36067\end{array}$ & $\begin{array}{l}\text { NNG } \\
n=36067\end{array}$ \\
\hline Gender, female (\%) & 57.63 & 52.79 & 57.12 & 57.42 \\
\hline Age (years), mean $\pm S D$ & $75.4 \pm 13.3$ & $71.3 \pm 11.4$ & $74.9 \pm 13.4$ & $75.1 \pm 12.7$ \\
\hline \multicolumn{5}{|l|}{ Race (\%) } \\
\hline White & 74.93 & 79.24 & 75.55 & 75.84 \\
\hline Black & 18.10 & 12.58 & 17.28 & 16.86 \\
\hline Hispanic & 3.02 & 3.29 & 3.18 & 3.30 \\
\hline Asian & 2.01 & 2.37 & 1.99 & 2.02 \\
\hline North American Native & 0.49 & 0.52 & 0.52 & 0.52 \\
\hline Other & 1.20 & 1.70 & 1.26 & 1.23 \\
\hline Unknown & 0.26 & 0.31 & 0.22 & 0.23 \\
\hline \multicolumn{5}{|c|}{27 chronic conditions from Chronic Conditions Data Warehouse (\%) } \\
\hline Diabetes & 100.00 & 100.00 & 100.00 & 100.00 \\
\hline Hypertension & 85.90 & 72.15 & 84.80 & 85.39 \\
\hline Anemia & 82.62 & 40.13 & 80.86 & 82.95 \\
\hline IHD & 64.69 & 42.94 & 63.00 & 63.60 \\
\hline $\mathrm{HF}$ & 57.55 & 24.56 & 54.25 & 54.86 \\
\hline Hyperlipidemia & 56.17 & 56.43 & 56.72 & 57.29 \\
\hline Cataract & 52.84 & 40.17 & 51.73 & 52.36 \\
\hline RA/OA & 52.71 & 35.26 & 50.99 & 51.73 \\
\hline COPD & 48.82 & 21.86 & 45.59 & 45.92 \\
\hline Depression & 46.31 & 21.68 & 43.31 & 42.95 \\
\hline CKD & 45.47 & 13.08 & 41.35 & 40.67 \\
\hline $\begin{array}{l}\text { Alzheimer's disease, } \\
\text { related disorders, or senile } \\
\text { dementia }\end{array}$ & 38.27 & 9.87 & 33.43 & 32.05 \\
\hline Stroke/TIA & 29.85 & 10.92 & 27.12 & 26.50 \\
\hline Acquired hypothyroidism & 27.18 & 17.25 & 26.47 & 26.62 \\
\hline Osteoporosis & 25.49 & 11.39 & 23.75 & 23.64 \\
\hline Atrial fibrillation & 24.88 & 10.84 & 23.27 & 22.97 \\
\hline Alzheimer's disease & 18.07 & 4.23 & 15.64 & 14.78 \\
\hline Asthma & 17.42 & 10.23 & 17.00 & 17.39 \\
\hline Glaucoma & 17.22 & 13.93 & 17.16 & 17.39 \\
\hline Benign prostatic hyperplasia & 15.87 & 11.77 & 15.60 & 15.81 \\
\hline Hip/Pelvic fracture & 9.96 & 2.04 & 8.06 & 7.28 \\
\hline AMI & 7.78 & 3.52 & 7.41 & 7.34 \\
\hline Colorectal cancer & 5.64 & 2.12 & 5.16 & 5.20 \\
\hline Prostate cancer & 5.34 & 4.24 & 5.33 & 5.42 \\
\hline Breast cancer & 4.69 & 3.39 & 4.55 & 4.66 \\
\hline Lung cancer & 3.61 & 1.25 & 3.43 & 3.39 \\
\hline Endometrial cancer & 0.95 & 0.49 & 0.86 & 0.82 \\
\hline
\end{tabular}

$\mathrm{AMI}$, acute myocardial infarction; CKD, chronic kidney disease; COPD, chronic obstructive pulmonary disorder; HF, heart failure; IHD, ischemic heart disease; MNG, malnourished group; NNG, normo-nourished group; OA, osteoarthritis; RA, rheumatoid arthritis; TIA, transient ischemic attack. 
Table 3 Time to death from diabetes diagnosis for all available data adjusted for age, gender, race, and other conditions

\begin{tabular}{|c|c|c|}
\hline Condition & $\begin{array}{l}\text { HR }(99.9 \% \mathrm{Cl}) \text { for } \\
\text { health condition }\end{array}$ & $\begin{array}{l}\mathrm{HR}^{*}(99.9 \% \mathrm{Cl}) \text { for } \\
\text { malnutrition within } \\
\text { health condition }\end{array}$ \\
\hline IHD† & 1.08 (1.08 to 1.09$)$ & 1.62 (1.61 to 1.63$)$ \\
\hline AMI‡ & 1.19 (1.19 to 1.20$)$ & 1.47 (1.44 to 1.49$)$ \\
\hline Stroke/TIA§ & 1.23 (1.23 to 1.24$)$ & 1.59 (1.57 to 1.60$)$ \\
\hline COPD§ & 1.49 (1.49 to 1.50$)$ & 1.66 (1.64 to 1.67$)$ \\
\hline CKD§ & 1.58 (1.58 to 1.59$)$ & 1.55 (1.54 to 1.56$)$ \\
\hline HF§ & 1.56 (1.55 to 1.56$)$ & 1.56 (1.55 to 1.57$)$ \\
\hline Malnutrition§ & 1.66 (1.65 to 1.66$)$ & \\
\hline Lung cancer§ & 2.70 (2.68 to 2.72$)$ & 1.61 (1.57 to 1.64$)$ \\
\hline
\end{tabular}

All $\mathrm{P}<0.0001$.

${ }^{\star}$ Effect of malnutrition within other common comorbid conditions. †Adjusted for all other conditions at time zero, excluding AMI. $\ddagger$ Adjusted for all other conditions at time zero, excluding IHD. $\S$ Adjusted for all other conditions at time zero.

AMI, acute myocardial infarction; COPD, chronic obstructive pulmonary disorder; CKD, chronic kidney disease; HF, heart failure; IHD, ischemic heart disease; TIA, transient ischemic attack.

people with diabetes was $16.5 \%$, with $5.3 \%$ malnourished at the time of diabetes diagnosis. When the effects of malnutrition and other common comorbid conditions on survival were analyzed after adjusting the confounders, the risk for mortality was increased in all available malnourished and propensity score-matched malnourished study populations. The risk for mortality was increased by $69 \%$ in beneficiaries with malnutrition, providing compelling evidence that malnutrition is an independent prognostic factor for survival among patients with diabetes. In fact, the risk for mortality observed for malnutrition is of a higher magnitude than the risk for mortality observed for any other chronic catabolic diseases associated with diabetes, such as CHF, CKD, and COPD. Considering the early and significant impact of malnutrition on survival identified by these analyses, appropriate malnutrition screening, assessment, diagnosis, and treatment in this population are critical.

Unfortunately, malnutrition is not widely recognized as a relevant comorbid condition in diabetes. This may be due in part to a misperception that PEM cannot coexist with overweight/obesity and/or use of nutritional assessment tools that use low BMI or underweight as part of the criteria, which can underestimate malnutrition in this population. Additionally, few studies have specifically evaluated malnutrition in older patients with diabetes. A prospective observational study of 1110 consecutive patients admitted across multiple hospitals in Spain reported that $21.2 \%$ of those with diabetes were malnourished, accounting for half of the inhospital deaths. Furthermore, $15.5 \%$ of the malnourished patients with diabetes

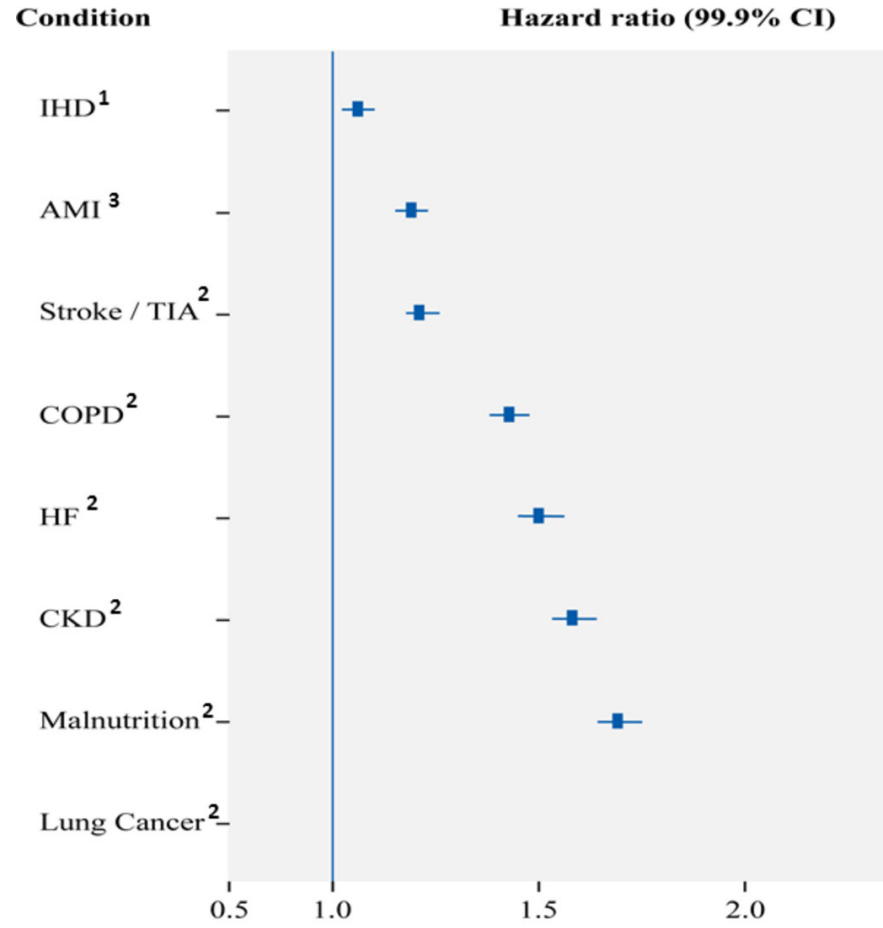

(A)
Hazard ratio $(99.9 \%$ CI)
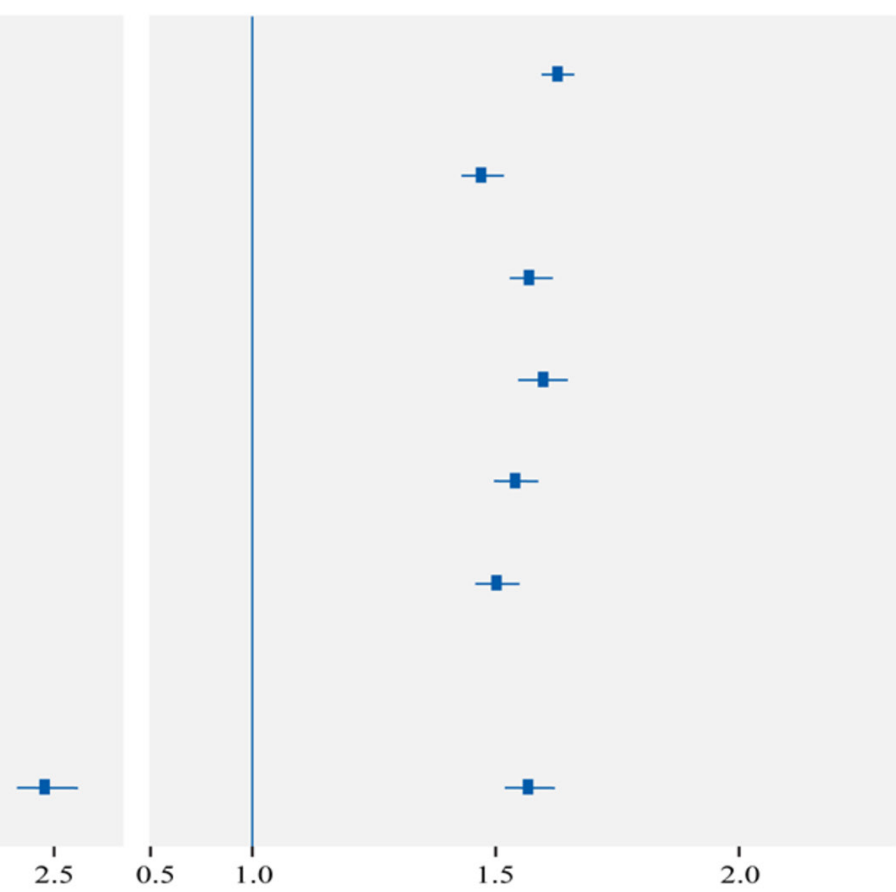

(B)

Figure 2 Time to death from diabetes diagnosis for propensity-matched sample adjusted for age, gender, race, and other conditions. HR and $99.9 \% \mathrm{Cl}$ for malnutrition and other comorbid conditions (A); effect of malnutrition within other common comorbid conditions (B). All $\mathrm{P}<0.0001$. ${ }^{1}$ Adjusted for all other conditions at time zero, excluding AMl; ${ }^{2}$ adjusted for all other conditions at time zero; ${ }^{3}$ adjusted for all other conditions at time zero, excluding IHD. AMI, acute myocardial infarction; CKD, chronic kidney disease; COPD, chronic obstructive pulmonary disorder; HF, heart failure; IHD, ischemic heart disease; TIA, transient ischemic attack. 


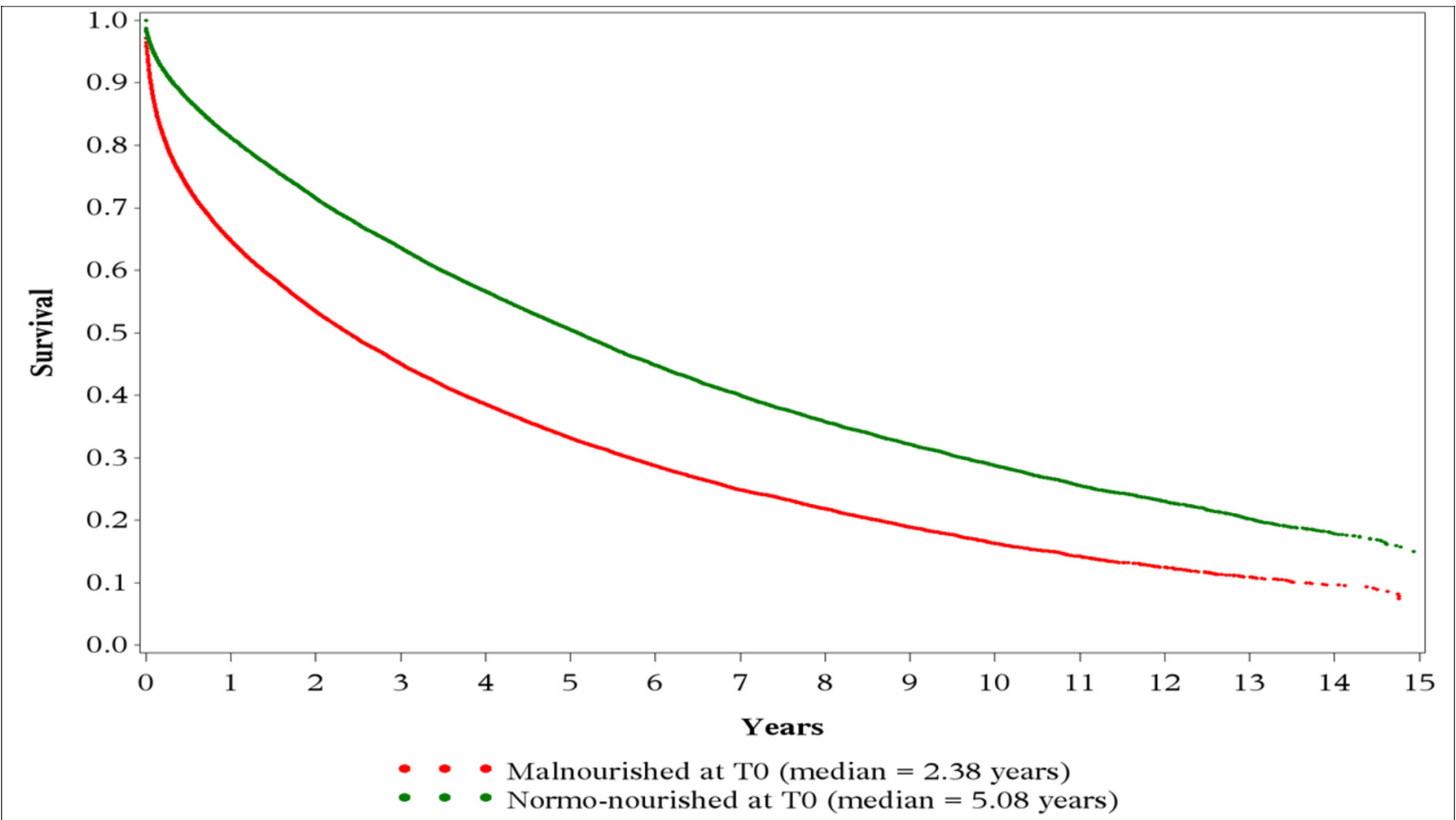

Figure 3 Kaplan-Meier survival curve for time to death from diabetes diagnosis (T0) using propensity score-matched sample for malnourished group and normo-nourished group.

were obese ${ }^{15}$ In a large single-center observational study of mortality risk in critically ill patients, obesity was protective against 30-day mortality except in those with malnutrition wherein the 90-day mortality risk in obese malnourished patients (with BMI $\geq 30.0 \mathrm{~kg} / \mathrm{m}^{2}$ ) was increased by $67 \%$ relative to normo-nourished patients. ${ }^{30}$ Thus, malnutrition

Table 4 The propensity score-matched differences between MNG and NNG in annual healthcare utilization

\begin{tabular}{|c|c|c|c|}
\hline & $\begin{array}{l}\text { MNG } \\
\text { (per year) }\end{array}$ & $\begin{array}{l}\text { NNG } \\
\text { (per year) }\end{array}$ & $\begin{array}{l}\text { Median difference/ } \\
\text { year } \\
(99.9 \% \mathrm{Cl})\end{array}$ \\
\hline Part $A+B+D$ & $\$ 36079$ & $\$ 20787$ & $\begin{array}{l}\$ 12259(\$ 11540 \text { to } \\
\$ 13004)^{*}\end{array}$ \\
\hline Part A & $\$ 22258$ & $\$ 10508$ & $\begin{array}{l}\$ 8775(\$ 8229 \text { to } \\
\$ 9365)^{\star}\end{array}$ \\
\hline Part B & $\$ 8840$ & $\$ 6262$ & $\begin{array}{l}\$ 2113(\$ 1921 \text { to } \\
\$ 2342)^{*}\end{array}$ \\
\hline Part D & $\$ 577$ & $\$ 717$ & $\$ 0(\$ 0$ to $\$ 0) \dagger$ \\
\hline
\end{tabular}

Median and $99.9 \% \mathrm{Cl}$ from propensity-matched sample period from year of diabetes diagnosis to year of death or 2014.

Part $A=$ claims for inpatient medical care, outpatient medical care, skilled nursing facility, non-institutional provider, home health, hospice services from inpatient medical care.

Part $B=$ claims for outpatient medical care.

Part $D=$ prescription drug information from the prescription drug events file.

${ }^{*} \mathrm{MNG}>\mathrm{NNG}, \mathrm{P}<0.0001$

$\dagger P=0.87$.

MNG, malnourished group at time zero; NNG, normo-nourished group at time zero. does occur with relatively high prevalence in the context of elevated body weight, and as such presents an interesting paradox. In this current study, $10.22 \%$ of the total number of diagnoses were related either with underweight or severe malnutrition (ie, Kwashiorkor-like syndrome or marasmus), suggesting that the majority of diagnoses

Table 5 OR for annual healthcare utilization in propensity score-matched MNG and NNG adjusted for age, gender, ethnoracial identity, and 26 disease conditions

\begin{tabular}{ll}
\hline Variable & OR $^{*}(99.9 \% \mathrm{Cl})$ \\
\hline $\begin{array}{l}\text { Acute inpatient covered days per } \\
\text { year }\end{array}$ & $3.08(2.87$ to 3.30$)$ \\
$\begin{array}{l}\text { Other inpatient covered days per } \\
\text { year }\end{array}$ & $2.07(1.93$ to 2.23$)$ \\
$\begin{array}{l}\text { Skilled nursing facility covered days } \\
\text { per year }\end{array}$ & $1.86(1.74$ to 1.99$)$ \\
\hline Hospice covered days per year & $1.23(1.15$ to 1.32$)$ \\
$\begin{array}{l}\text { Acute inpatient stays per year } \\
\text { Other inpatient stays per year }\end{array}$ & $2.50(2.33$ to 2.67$)$ \\
\hline $\begin{array}{l}\text { Skilled nursing facility stays per year } \\
\text { Hospice stays per year }\end{array}$ & $1.97(1.84$ to 2.10$)$ \\
\hline Hospital readmissions per year & $1.32(1.23$ to 1.41$)$ \\
\hline
\end{tabular}

All $\mathrm{P}<0.0001$

${ }^{*}$ Odds of greater number in MNG over odds of greater number in NNG.

MNG, malnourished group at time zero; NNG, normo-nourished group at time zero. 
were related to clinical characteristics potentially independent of weight status. Currently, there is no biomarker used to diagnose PEM. According to the consensus by the Academy of Nutrition and Dietetics and the American Society for Parenteral and Enteral Nutrition, malnutrition is assessed based on weight loss (either fat or muscle), in combination with other clinical assessments such as energy intake, fluid accumulation, and/or fatigue. ${ }^{31}$ Use of assessment tools based on these guidelines should be helpful in standardizing malnutrition diagnoses for ICD-10 in at-risk populations, independent of body weight. In light of the results of this current study, however, further research on malnutrition assessment methods for patients with diabetes is needed and nutrition assessment for malnutrition at the time of diabetes diagnosis is critical.

Nutrition is an integral part of diabetes care; however, there may be additional considerations for older adults such as reduced energy requirements, decreased taste and smell sensitivities, decreased food variety and appetite, polypharmacy, difficulty in preparing food, social isolation and depression. ${ }^{52}$ Importantly, a cost-effective intervention for malnutrition can include oral nutritional supplements. ${ }^{334}$ A systematic review of 49 studies (not specifically patients with diabetes) reveals that nutritional supplements can improve nutrient intakes and mortality outcomes in malnourished older patients. ${ }^{35}$ A recent randomized controlled trial of 652 malnourished inpatients with COPD, CHF, AMI, and pneumonia showed that initiation of a specialized high-protein nutrition intervention with beta-hydroxy-beta-methylbutyrate during hospitalization and continuation postdischarge significantly decreased mortality compared with placebo receiving similar standard of care. The authors concluded that nutritional interventions that are effective in maintaining lean body mass benefit survival. ${ }^{36}$ While these findings were not specific for diabetes populations, the findings can have important implications as patients with diabetes also have higher incidence of sarcopenia despite a higher BMI, as a result of decreased antiproteolytic actions from insulin resistance or insulinopenia. ${ }^{37}$

According to the American Diabetes Association in 2012, the total estimated cost of diagnosed diabetes was $\$ 245$ billion, including $\$ 176$ billion for direct medical costs and $\$ 69$ billion for reduced productivity. ${ }^{2}$ A major part of this cost $(59 \%)$ for diabetes care in adults aged 65 years or older is provided by Medicare in the USA. ${ }^{2}$ Malnutrition in patients with diabetes further compounded the economic cost of diabetes as demonstrated by this analysis, in which there was a $58 \%$ increase in the cost of average annual healthcare in malnourished patients with diabetes compared with those who were normo-nourished. This increase in cost was attributed to longer durations of hospital stays and increased nursing and pharmacy costs. The diagnosis and treatment of malnutrition could result in a significant reduction of healthcare expenses in elderly population with diabetes.

The strength of the study is that it includes a large study cohort derived from the CMS database, which offers the advantages of a large population coverage, clinical validity of the Medicare data, and ease of data availability. Similar to other retrospective studies, this study has limitations. The analyses are limited by the lacunae in the CMS database such as non-availability of laboratory results and limited clinical information. The results of this study are limited to Medicare beneficiaries only, and therefore may not be generalizable to other populations. Malnutrition is recognized to be underdiagnosed, especially in those who are considered overweight or obese, which include many patients with diabetes. The baseline differences in multiple variables in the cohorts are the shortcomings of this study, although these were adjusted by using propensity scores for age, gender, ethnoracial identity, and 26 other disease conditions. Furthermore, cause and effect relationships of malnutrition to other chronic conditions prior to diabetes diagnosis in this retrospective analysis could not be studied: yet, in all analyses, malnutrition stood out to have a significant effect on survival time even within each chronic condition. Although the main focus of this study was mortality as a primary variable with cost as a secondary variable, the role of malnutrition on the QoL in patients with diabetes also needs to be evaluated.

In conclusion, this study confirmed malnutrition as a significant comorbidity for CMS beneficiaries with diabetes, affecting survival both independently and within other common comorbidities, providing compelling evidence that malnutrition is an independent prognostic factor for survival among patients with diabetes. Malnutrition in patients with diabetes further compounded the cost of diabetes care with a well over $50 \%$ increase. The results of this study may help guide nutrition assessment and clinical decision-making for the betterment of care for patients with diabetes, as well as lead to potentially significant cost savings. Given that patients experience short-term and long-term impact on survival after being diagnosed with diabetes, malnutrition assessment and diagnosis should be crucially considered and initiated at the time of diabetes diagnosis.

Acknowledgements The authors would like to thank Ramu Periyasamy for assistance with the preparation of this manuscript and Dr Osama Hamdy for initial consultation.

Contributors The authors meet the criteria for authorship recommended by the International Committee of Medical Journal Editors and take full responsibility for all content in the manuscript and all editorial decisions. Concept and development and design of study: NA, SG, YC, VAM; data collection, analysis and interpretation: NA, SG, YC, VAM, SC, ML, JIM; development and review of the manuscript: NA, SG, YC, VAM, ML, JIM; finalization and approval of the manuscript: NA, SG, YC, VAM, SC ML, JIM; guarantor of the study: NA.

Funding This study was sponsored by Abbott Nutrition.

Competing interests All except JIM are shareholders and employees of Abbott. JIM has served in the advisory board of Abbott Nutrition and has been a compensated advisor of Abbott Nutrition.

Provenance and peer review Not commissioned; externally peer reviewed.

Open Access This is an Open Access article distributed in accordance with the Creative Commons Attribution Non Commercial (CC BY-NC 4.0) license, which permits others to distribute, remix, adapt, build upon this work non-commercially, and license their derivative works on different terms, provided the original work is properly cited and the use is non-commercial. See: http://creativecommons.org/licenses/by-nc/4.0/ 
(c) Article author(s) (or their employer(s) unless otherwise stated in the text of the article) 2018. All rights reserved. No commercial use is permitted unless otherwise expressly granted.

\section{REFERENCES}

1. World Health Organization. Diabetes Fact Sheet, 2016. http://www. who.int/mediacentre/factsheets/fs312/en/. (accessed 17 Oct 2016).

2. American Diabetes Association. Statistics About Diabetes, 2016. http://www.diabetes.org/diabetes-basics/statistics/. (accessed 17 Oct 2016)

3. American Diabetes Association. Economic costs of diabetes in the U.S. in 2012. Diabetes Care 2013;36:1033-46.

4. Boyle JP, Thompson TJ, Gregg EW, et al. Projection of the year 2050 burden of diabetes in the US adult population: dynamic modeling of incidence, mortality, and prediabetes prevalence. Popul Health Metr 2010;8:29

5. Kirkman MS, Briscoe VJ, Clark N, et al. Diabetes in older adults. Diabetes Care 2012;35:2650-64.

6. Agarwal E, Miller M, Yaxley A, et al. Malnutrition in the elderly: a narrative review. Maturitas 2013;76:296-302.

7. Barker LA, Gout BS, Crowe TC, et al. identification and impact on patients and the healthcare system. Int J Environ Res Public Health 2011;8:514-27.

8. Freijer K, Nuijten MJ, Schols JM. The budget impact of oral nutritional supplements for disease related malnutrition in elderly in the community setting. Front Pharmacol 2012;3:78.

9. Lim SL, Ong KC, Chan YH, et al. Malnutrition and its impact on cost of hospitalization, length of stay, readmission and 3-year mortality. Clin Nutr 2012;31:345-50.

10. Willis H. Causes, assessment and treatment of malnutrition in older people. Nurs Older People 2017;29:20-5.

11. Goates S, Du K, Braunschweig CA, et al. Economic Burden of Disease-Associated Malnutrition at the State Level. PLoS One 2016;11:e0161833.

12. Stratton RJ, Hébuterne $X$, Elia M. A systematic review and metaanalysis of the impact of oral nutritional supplements on hospital readmissions. Ageing Res Rev 2013;12:884-97.

13. Ahmed T, Haboubi N. Assessment and management of nutrition in older people and its importance to health. Clin Interv Aging 2010;5:207-16.

14. Ogden CL, Carroll MD, Fryar CD, et al. Prevalence of Obesity Among Adults and Youth: United States, 2011-2014. NCHS Data Brief 2015;219:1-8.

15. Sanz París A, García JM, Gómez-Candela C, et al. Malnutrition prevalence in hospitalized elderly diabetic patients. Nutr Hosp 2013;28:592-9.

16. Henry J. Kaiser Family Foundation: Medicare at a glance. http:// $\mathrm{kff}$. org/medicare/fact-sheet/medicare-at-a-glance-fact-sheet/ (accessed 17 Oct 2016).

17. Chronic Conditions Data Warehouse: National CMS Medicare and Medicaid Research database. https://www.ccwdata.org/web/guest/ about-ccw (accessed 17 Oct 2016).

18. The Official U.S. Government Site for Medicare. https://www. medicare.gov/ (accessed 17 Oct 2016).

19. Austin PC. The use of propensity score methods with survival or time-to-event outcomes: reporting measures of effect similar to those used in randomized experiments. Stat Med 2014;33:1242-58.
20. Austin PC. An Introduction to Propensity Score Methods for Reducing the Effects of Confounding in Observational Studies. Multivariate Behav Res 2011;46:399-424.

21. Bergstralh EJ, Kosanke JL. Computerized matching of cases to controls. Technical Report Number 56. Rochester, MN: Mayo Foundation, 1995.

22. Faries DE, Leon AC, Haro JM, et al; Analysis of observational health care data using SAS. Cary, NC: SAS Institute, 2010.

23. Chronic Conditions Data Warehouse: medicare Data User Guide. https://www.ccwdata.org/web/guest/user-documentation (accessed 17 Oct 2016)

24. Morrish NJ, Wang SL, Stevens LK, et al. Mortality and causes of death in the WHO Multinational Study of Vascular Disease in Diabetes. Diabetologia 2001;44:S14-21.

25. Rao Kondapally Seshasai S, Kaptoge S, Thompson A, et al. Diabetes mellitus, fasting glucose, and risk of cause-specific death. N Engl J Med 2011;364:829-41.

26. Vischer UM, Perrenoud L, Genet C, et al. The high prevalence of malnutrition in elderly diabetic patients: implications for anti-diabetic drug treatments. Diabet Med 2010;27:918-24.

27. Rasheed S, Woods RT. An investigation into the association between nutritional status and quality of life in older people admitted to hospital. J Hum Nutr Diet 2014:27:142-51.

28. Sanz-Paris A, Boj-Carceller D, Lardies-Sanchez B, et al. Health-Care Costs, Glycemic Control and Nutritional Status in Malnourished Older Diabetics Treated with a Hypercaloric Diabetes-Specific Enteral Nutritional Formula. Nutrients 2016;8:153.

29. Söderström L, Rosenblad A, Thors Adolfsson E, et al. Malnutrition is associated with increased mortality in older adults regardless of the cause of death. Br J Nutr 2017;117:532-40.

30. Robinson MK, Mogensen KM, Casey JD, et al. The relationship among obesity, nutritional status, and mortality in the critically ill. Crit Care Med 2015;43:87-100.

31. White JV, Guenter P, Jensen G, et al. Consensus statement: Academy of Nutrition and Dietetics and American Society for Parenteral and Enteral Nutrition: characteristics recommended for the identification and documentation of adult malnutrition (undernutrition). JPEN J Parenter Enteral Nutr 2012;36:275-83.

32. Gonzalez-Campoy JM, St Jeor ST, Castorino K, et al. Clinical practice guidelines for healthy eating for the prevention and treatment of metabolic and endocrine diseases in adults: cosponsored by the American Association of Clinical Endocrinologists/the American College of Endocrinology and the Obesity Society. Endocr Pract 2013;19:1-82.

33. Zhong Y, Cohen JT, Goates S, et al. The Cost-Effectiveness of Oral Nutrition Supplementation for Malnourished Older Hospital Patients. Appl Health Econ Health Policy 2017;15:75-83.

34. Elia M, Normand C, Norman K, et al. A systematic review of the cost and cost effectiveness of using standard oral nutritional supplements in the hospital setting. Clin Nutr 2016;35:370-80.

35. Milne AC, Potter J, Avenell A, Vivanti A, et al. Protein and energy supplementation in elderly people at risk from malnutrition. Cochrane Database Syst Rev 2005;2:CD003288.

36. Deutz NE, Matheson EM, Matarese LE, et al. Readmission and mortality in malnourished, older, hospitalized adults treated with a specialized oral nutritional supplement: A randomized clinical trial. Clin Nutr 2016;35:18-26.

37. Umegaki H, Sarcopenia UH. Sarcopenia and diabetes: Hyperglycemia is a risk factor for age-associated muscle mass and functional reduction. J Diabetes Investig 2015;6:623-4. 